\title{
Penerapan Konsep Finite State Automata Dalam Proses Pendaftaran Kelas Kursus Bahasa Inggris Pada Tempat Kursus
}

\author{
Faruq Aziz, Fadillah Said, Adjat Sudrajat
}

\begin{abstract}
Research on website-based test applications for digital course registration in order to make it easier for course institutions to determine classes that are consistent and effective and efficient. This research provides alternative solutions for course institutions for class selection or course program that is suitable for users who will study at the place of the course which is costeffective and time-consuming too. In this study a course registration application is designed by integrating a website and database to retrieve data after the user has tested. It is intended that users who want to learn English can receive a choice of classes or programs in accordance with their abilities and initial knowledge. This minimizing test instructor errors in determining class and program choices that will be obtained by the user. In this study using the Finite State Automata (FSA) method to discuss the NFA type FSA model can be implemented in the registration process to the user (member) where the course is expected as needed and can better understand how the process of class or program selection is effective and right on target.
\end{abstract}

Index Terms - Classroom Registration Application; English Test; Finite State Automata.

Abstrak-Penelitian tentang aplikasi tes berbasis website untuk pendaftaran kelas kursus secara digital guna mempermudah lembaga kursus untuk menentukan kelas yang konsisten dan efektif serta efisien. Penelitian ini memberikan solusi alternatif bagi lembaga kursus untuk pemilihan kelas atau program kursus yang sesuai bagi pengguna yang akan belajar pada tempat kursus tersebut yang hemat biaya dan waktu juga. Pada penelitian ini didesain aplikasi pendaftaran kursus dengan mengintegrasikan website dan database untuk mengambil data setelah pengguna melakukan tes. Hal ini bertujuan agar pengguna yang hendak belajar bahasa inggris dapat menerima pilihan kelas atau program sesuai dengan kemampuan dan pengetahuan awal. Sehingga

Faruq Aziz,Ilmu Komputer, STMIK Nusa Mandiri, Jakarta, Indonesia, email : 14002420@nusamandiri.ac.id

Fadillah Said, IImu Komputer, STMIK Nusa Mandiri, Jakarta, Indonesia, email : 14002413@nusamandiri.ac.id

Adjat Sudrajat, IImu Komputer, STMIK Nusa Mandiri, Jakarta, Indonesia, email : adjat.ajt@nusamandiri.ac.id meminimalisasi kesalahan instruktur test dalam penentuan pilihan kelas dan program yang akan didapat oleh pengguna. Dalam penelitian ini menggunakan metode Finite State Automata (FSA) guna membahas model FSA jenis NFA dapat diimplementasikan dalam proses pendaftaran pada pengguna (member) tempat kursus yang diharapkan sesuai kebutuhan dan dapat lebih memahami bagaimana proses pemilihan kelas atau program yang efektif dan tepat sasaran.

Kata Kunci- Bahasa dan Automata; Finite State Automata; Vending Machine;

\section{PENDAHULUAN}

$\mathrm{T}$ empat Kursus merupakan salah satu pendidikan yang diberikan diluar sekolah resmi (nonformal) untuk mengembangkan kemampuan dan keterampilan diri [1]. Pada tempat kursus biasanya seseorang akan melakukan perencanaan program latihan yang merupakan kegiatan awal untuk menentukan urutan tindakan, perkiraan biaya, sarana prasarana, penggunaan waktu, penggunaan sumber daya manusia untuk suatu program latihan di tempat kursus yang didasarkan atas data dengan memperhatikan prioritas yang wajar dan efisien untuk tercapainya tujuan perencanaan program kursus. Beberapa tempat kursus menyediakan seorang instruktur yang membantu murid (member) dalam menjalankan program kursus secara baik dan benar, memilih program yang tepat untuk setiap member, memastikan para member melakukan program kursus yang benar dan sesuai dengan ketentuan, serta menambah pengetahuan member dalam menyelesaikan masalah belajar dan panduan belajar. Instruktur dituntut harus benar - benar dapat menentukan program yang paling sesuai dengan kebutuhan member demi mencapai hasil yang diharapkan yang dalam pelaksanaannya tidak jarang tidak tepat sasaran. Hal ini menimbulkan masalah dimana member kadang merasa jenuh karena kelas yang diambil terlalu gampang ataupun sebaliknya. Dalam penelitian ini mencoba memberikan solusi dengan membuat website yang berisi pertanyaan berupa tes 
secara online guna menentukan kelas apa yang cocok bagi member serta memberikan sertifikat bagi member sehingga bisa digunakan sebagai acuan guna mendaftar dalam tempat kursus dan membantu tempat kursus untuk memilah member dengan konsisten serta efektif dan efisien.

Finite State Automata (FSA) merupakan mesin abstrak berupa sistem model matematika dengan masukan dan keluaran diskrit terdiri dari string dan label dengan output terdiri dari 0s 1s yang dapat mengenali bahasa paling sederhana (bahasa reguler) yang menangkap pola dalam data dan dapat diimplementasikan secara nyata sehingga dapat dipahami oleh logika manusia[2][3][4]. FSA adalah model matematika yang dapat menerima input dan mengeluarkan output yang memiliki state yang berhingga banyaknya dan dapat berpindah dari satu dari jenisnya yaitu FSA terdapat mesin bahasa yang dapat mengenali, menerima dan menolak yang terdapat pada mesin FSA jenis Deterministic Finite Automata (DFA) dan Non-deterministic Finite Automata (NFA).[5][6]. FSA memiliki sifat-sifat seperti pita masukkan (input tape) berisi rangkaian simbol (string) yang berasal dari himpunan alphabet / simbol, setiap kali setelah membaca satu karakter, posisi read head akan berada pada simbol berikutnya, setiap saat FSA berada dalam status tertentu serta banyaknya status yang berlaku bagi FSA adalah berhingga.[7][8].

Terdapat dua tingkatan FSA yang digunakan pada penelitian ini. Pada tingkatan pertama yang dikenali adalah pola $\mathrm{V}$, K, dan KV. Hasil pengenalan FSA dalam suatu tingkatan menjadi masukan (input) bagi FSA tingkatan berikutnya. Dalam gambar 1 digambarkan diagram transisi FSA tingkatan pertama[20].

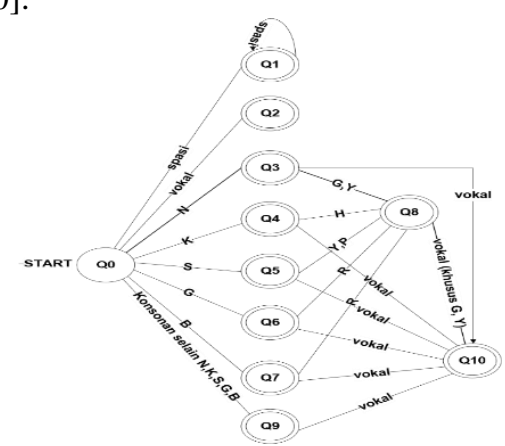

Gambar 1. Diagram Transisi FSA Tingkatan Pertama

Pada tingkatan kedua FSA dapat mengenali 12 suku kata dengan pola $\mathrm{V}, \mathrm{VK}, \mathrm{KV}, \mathrm{VKK}, \mathrm{KVK}, \mathrm{KKV}$, KVKK, KKVK, KKKV, KKVKK, KKKVK, dan KVKKK. Dalam gambar 2 digambarkan diagram transisi FSA tingkatan kedua.

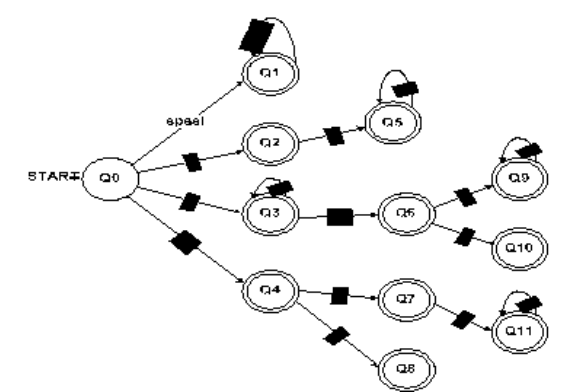

Gambar 2. Diagram Transisi FSA Tingkatan Kedua

Pada penelitian ini konsep penerapan FSA digunakan untuk mengenal serta menangkap pola dalam proses aplikasi tes ini. Teori Automata merupakan tools yang efektif untuk merancang, mengotomatisasi dan mengoptimalkan perilaku kontrol komputer sistem. Pemodelan sistem keadaan hingga dan mendefinisikan sekumpulan kata-kata terbatas adalah aplikasi automata terbatas dalam konstruksi kompiler[9][10]. Automata muncul dengan beberapa aplikasi modern, misalnya, optimasi, program berbasis logika, spesifikasi dan verifikasi protokol. NFA dan DFA adalah jenis utama yang digunakan pada berbagai tingkat pemodelan dan spesifikasi [11].

NFA berbasis matematika teknik memiliki model mesin abstrak yang bisa direpresentasikan menggunakan diagram. Model seperti itu bisa digunakan untuk melakukan perhitungan input dengan bergerak melalui serangkaian urutan transisi dan konfigurasi. Di negara manapun, NFA menggunakan urutan simbol dan transformasi input ke status baru hingga semua simbol input telah digunakan. Untuk simbol input apapun di NFA status selanjutnya tidak unik ditentukan oleh fungsi transisi. Transisi selanjutnya mungkin tidak menghasilkan, tunggal atau sekumpulan dan karenanya disebut nondeterministic[12][13]. Fungsi transisi dalam NFA menghitung status berikutnya berdasarkan kondisi saat ini dan alfabet di setiap langkah perhitungan. Jika mungkin mencapai salah satu state penerima dengan menggunakan serangkaian transisi maka input diterima. FSA jenis NFA merupakan model yang digunakan untuk merancang aplikasi yang dapat membantu dalam workout plan ini [14][12]. Teori bahasa bertindak sebagai sarana komunikasi baik sesama manusia ataupun antara manusia dan mesin. Sedangkan teori automata merupakan teori mengenai mesin-mesin abstrak, dan berkaitan erat dengan teori bahasa formal. Teori bahasa dan automata sangat berguna untuk pengembangan ilmu komputer lebih lanjut baik dalam perangkat keras (hardware) dan perangkat lunak (software) [15]. Untuk menggambarkan alur aktivita FSA, digunakan menggunakan Unified Modelling Language (UML) yang terdiri dari usecase diagram dan Activity diagram. UML adalah bahasa yang digunakan untuk menjelaskan kebutuhan, membuat analisa dan desain serta menggabarkan arsitektur [21]. Use case diagram diagram akan menjalaskan interaksi antara penggukan dan sistem yang dirancang, sedangakn activity diagram aliran kerja dari sistem yang dirancang [22]. 
Penggunaan Vending Machine (VM) menggunakan FSA juga dilakukan pada Desain VM Rokok terintegrasi KTP untuk mengurangi perokok aktif yang berusia dibawah umur [11]. Bahkan FSA tidak hanya digunakan dalam VM, dalam Identifikasi File JPEG dengan Metode Signature-Based Carving FSA digunakan untuk dapat mengidentifikasi dan merecoveryfile JPEG [9].Penerapan metode ini pada Proses Pendaftaran Kelas Kursus dilakukan untuk merancang FSA Proses Pendafataran Kelas Kursus pada Tempat Kursus menggunakan FSA sehingga dapat dikembangkan dan bermanfaat dalam pemilihan kelas secara efektif dan efisien.

\section{LANDASAN TEORI}

\section{A. Finite State Automata}

FSA adalah model matematika yang dapat menerima input dan mengeluarkan output yang memiliki state yang berhingga banyaknya dan dapat berpindah dari satu dari jenisnya yaitu FSA terdapat mesin bahasa yang dapat mengenali, menerima dan menolak yang terdapat pada mesin FSA jenis Deterministic Finite Automata (DFA) dan Non-deterministic Finite Automata (NFA) [11]. Secara formal FSA dinyatakan oleh 5 tupel atau $\mathrm{M}=(\mathrm{Q}, \Sigma, \delta, \mathrm{S}, \mathrm{F})$ dimana:

$\mathrm{Q}=$ himpunan state/kedudukan

$\Sigma=$ himpunan simbol input/masukan/abjad

$\delta=$ fungsi transisi

$\mathrm{S}=$ state awal/kedudukan awal (initial state),

$\mathrm{S} \in \mathrm{Q} F=$ himpunan state akhir, $\mathrm{F} \cap \mathrm{Q}$ (jumlah state akhir pada suatu FSA bisa lebih dari satu)

\section{B. Non-deterministic Finite Automata}

Sebuah Nondeterministic Finite Automaton (NFA) merupakan jenis finite state machine (FSM) dimana salah satu nextstate tidak sepenuhnya ditentukan oleh current state ataupun input. Himpunan dari possible next states menyatakan bahwa automata dapat berpindah dari state tertentu (qa) ke state yang lain (qb) sebagai tanggapan terhadap suatu input $(\alpha)$. Dalam NFA, jumlah start state dan transisi untuk setiap anggota himpunan input $(\Sigma)$ tidak harus tepat satu[25].

\section{METODE PENELITIAN}

Metodologi yang diterapkan pada penelitian ini sebagaimana disajikan pada gambar 3.Tahapan pertama yang dilakukan adalah memahami pemilihan kelas kursus, meliputi:

1) memahami konsep tingkatan kursus

2) distribusi pengenalan kepada lembaga kursus dan masyarakat

3) mekanisme penentuan kelas kursus.
Berdasarkan hal tersebut, pada tahapan selanjutnya mencoba menguraikan konsep finite state automata pada pemilihan kelas kursus. Selanjutnya melakukan perancangan sistem akses bagi admin untuk pengisian soal dan bukti.

Tahapan berikutnya adalah melakukan perancangan diagram state. Berdasarkan diagram state tersebut akan dibuat desain dan evaluasi atas fitur-fiturnya.

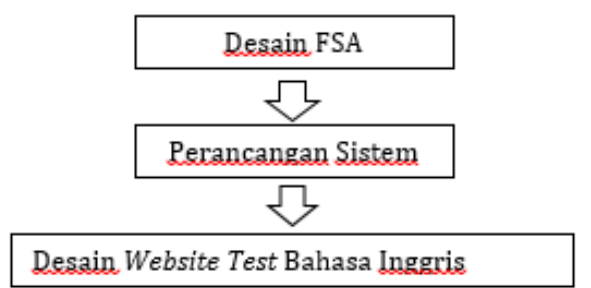

Gambar 3. Kerangka Kerja Konseptual Aplikasi

\section{HASIL DAN PEMBAHASAN}

\section{Finite state automata (FSA)}

Berikut merupakan beberapa penjelasan mengenai simbol pada FSA.

\begin{tabular}{l|l} 
Tabel 1. Simbol Pada FSA [23] \\
\hline & State \\
\hline$\longrightarrow$ & Final State \\
\hline$\longrightarrow$ & Transition \\
\hline
\end{tabular}

Metode yang digunakan yaitu dengan menggunakan finite state, yang mana jika diambil contoh kasus sebagai berikut:

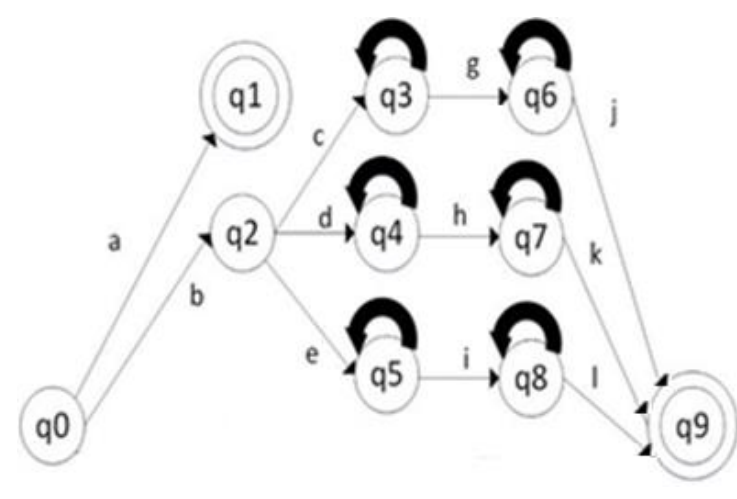

Gambar 4. Metode FSA proses pendaftaran kursus

Keterangan:

$\mathrm{q} 0=$ Status Awal

$\mathrm{q} 1=$ Mengikuti hanya mengambil 1 bagian program Writing)

(Listening / Speaking / Grammar /

q2= Pendaftaran sebagai Member (murid) 
q3= Terdaftar sebagai Member dengan kategori Beginner

q4= Terdaftar sebagai Member dengan kategori Intermmediate

q5= Terdaftar sebagai Member dengan kategori Advance

q6 = Mendapatkan kartu MemberBeginner

q7 = Mendapatkan kartu MemberIntermmediate

q8 = Mendapatkan kartu MemberAdvance

q9 = Sesi Akhir Kursus

$\mathrm{a}=$ Member mengambil 1 Bagian Program

\section{(Listening / Speaking / Grammar / Writing)}

$\mathrm{b}=$ Registrasi pendaftaran sebagai member

$\mathrm{c}=$ Sistem memverifikasi member masuk dalam kategori Beginner

$\mathrm{d}=$ Sistem memverifikasi member masuk dalam kategori Intermmediate

$\mathrm{e}=$ Sistem memverifikasi member masuk dalam kategori Advance

$\mathrm{g}=$ Member mengambil program Beginner

$\mathrm{h}=$ Member mengambil program Intermmediate

$\mathrm{i}=$ Member mengambil program Advance

$\mathrm{j}=$ Member melakukan sesi program Program

Beginner Bersama Instruktur

$\mathrm{k}=$ Member melakukan sesi program Program Intermmediate Bersama Instruktur

$1=$ Member melakukan sesi program Program Advance Bersama Instruktur

\section{Perancangan Sistem}

Untuk perancangan sistem, pada penelitian ini menggunakan UML yang terdiri dari:

\section{a. Use Case Diagram}

Usecase Diagram menunjukkan interaksi antara Usecase dan aktor. Diagram ini menggambarkan model lengkap tentang apa saja yang dilakukan di dalam website test/quiz, siapa yang berperan diluar dan di dalamnya.

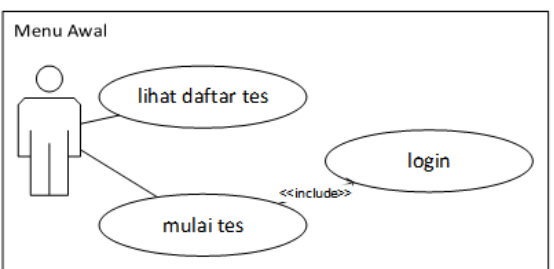

Gambar 5. Use Case DiagramMenu Awal

Pada gambar 5 menjelaskan usecase diagram dengan aktor pengguna yang dapat melakukan quis dan melihat daftar quis. Setelah proses pemilihan mulai test, barulah pengguna dapat login kesistem dan melakukan test.

\section{b. Activity Diagram}

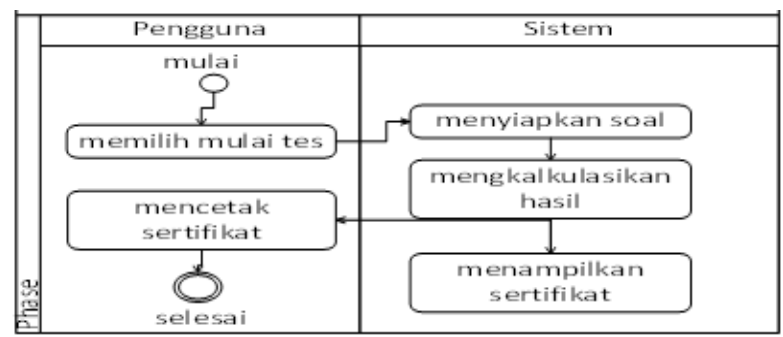

Gambar 6. Activity Diagram memulai test

Pada gambar 6 menampilkan activity diagram memilih mulai kuis. Saat awal, sistem akan menampilkan tampilan mulai kuis dilayar. Kemudian sistem menyiapkan soal lalu mengkalulasikan hasil dari pengguna dan menampilkan hasilnya dalam bentuk sertifikat yang bisa disimpan oleh pengguna.

\section{Desain Aplikasi Test Bahasa Inggris}

Berdasarkan dari penelitian yang sudah ada penulis mendapat inspirasi untuk mendesain aplikasi tes pengetahuan bahasa inggris yang menyesuaikan model NFA yang telah dibuat, Berikut merupakan gambar dari aplikasi permainan yang di desain.

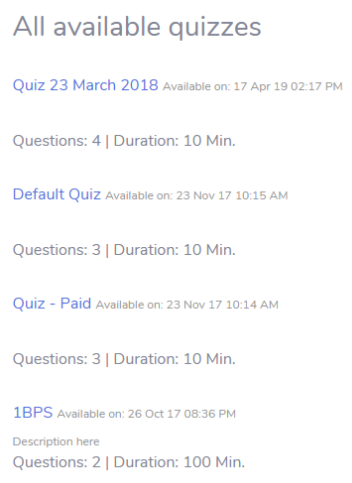

Gambar 7. Halaman Awal

Halaman ini dapat terlihat ketika pengguna membuka aplikasi, pada halaman ini pengguna akan melihat berbagai macam jenis test. 


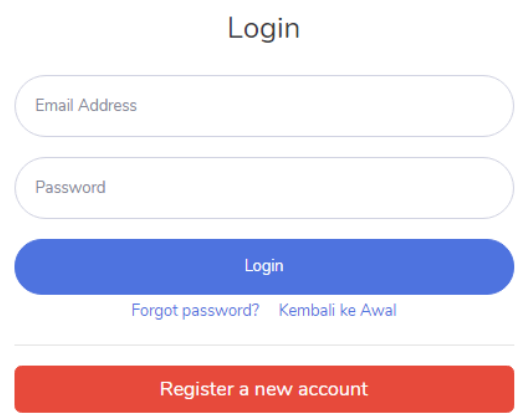

Gambar 8. Halaman Menu Login

Pada halaman ini pengguna bisa login untuk memulai tes dan apabila belum memiliki akun bisa daftar terlebih dahulu.

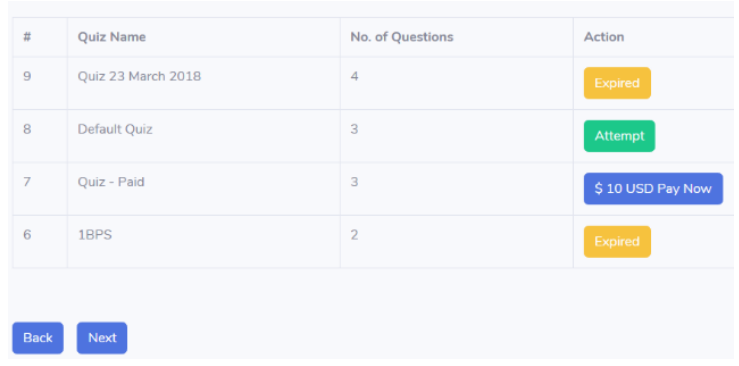

Gambar 9. Halaman Menu Pilihan Test

Pada halaman ini pengguna dapat memilih jenis tes sesuai dengan waktu dan kondisi.
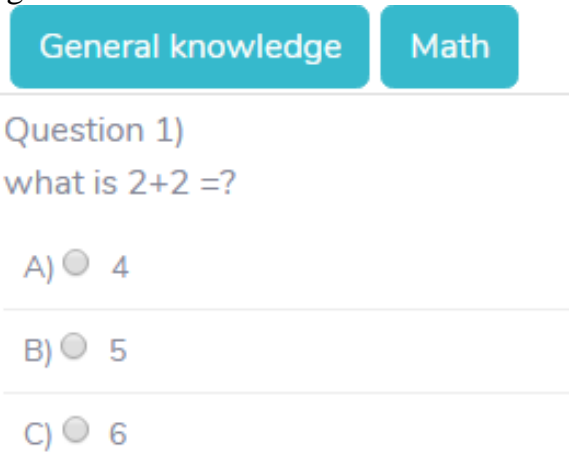

Gambar 10. Halaman Test

Pada halaman ini pengguna akan melakukan ujian test berupa menjawab pertanyaan-pertanyaan yang akan menentukan apakah pengguna akan masuk kelas beginner/intermediate/advance.

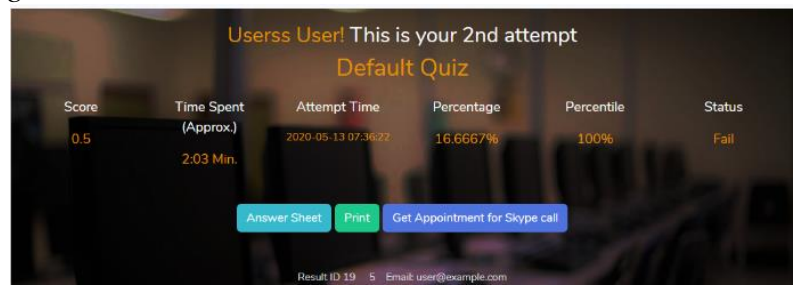

Gambar 11. Halaman Hasil

Pada halaman ini pengguna mendapatkan sertifikat dari hasil yang telah tercapai dan otomatis tersimpan serta terkirim via email.

\section{KESIMPULAN}

Finite state automata berjenis NFA sangat membantu dalam menentukan seseorang untuk menentukan pilihan program pendaftaran kelas dan memberi gambaran sistem yang cukup detail dalam menentukan program latihan yang tepat. dengan menggunakan pemodelan finite state automata jenis NFA pemodelan lebih cepat dan terstruktur. Hubungan dan transisi antar fungsional dalam aplikasi dengan mudah dapat didefinisikan dengan transisi antar state, sehingga dalam proses pengembangan tidak terjadi kesalahan pendefinisian hubungan antar fungsional. Penentuan Kelas disusun oleh sistem ditempatkan menggunakan stateyang telah diurutkan berdasarkan ketentuan dari masing-masing kriteria bentuk tubuh. Dengan Program ini, memberdiharapkan dapat terbantu dan mengetahui kelas yang benar dan sesuai dengan kemampuan dan pengetahuan masingmasing.

\section{REFERENSI}

M. Mulyadi, H. Hoiriah, ... D. S.-... (Indonesian J. on, and U. 2018, "Sistem Informasi Pendaftaran Kursus Berbasis Web pada Yayasan Musik Jakarta," ejournal.bsi.ac.id, vol. 3, no. 1, p. 9, 2018 .

A. M. Nisa and H. Kurniansyah, "Perancangan dan Implementasi Finite State Automata pada Pusheen Cat Maze Game dengan Adobe Flash," Res. Comput. Inf. Syst. Technol. Manag., vol. 2, no. 01, p. 13, 2019, doi: 10.25273/research.v2i1.4268.

[3] N. D. Wirasbawa, L. Benedict, B. G. Santoso, F. Farhan, and A. Kusnadi, "Penerapan Konsep Non-Deterministic Finite Automata Untuk Pembuatan Sereal Menggunakan Mesin Jual Otomatis Dengan Dua Sistem Pembayaran," Simp. Nas. Ilm., no. November, pp. 440-448, 2019, doi: 10.30998/simponi.v0i0.375.

[4] E. E. Ogheneovo, "A New Algorithm for Determining the Equivalence of Two Finite-State Automata," J. Adv. Math. Comput. Sci., vol. 29, no. 5, pp. 1-10, 2018, doi $10.9734 / \mathrm{jamcs} / 2018 / 37848$

[5] T. I. Saputra, F. Fauziah, and A. Gunaryati, "Simulasi Vending Machine Dengan Mengimplementasikan Finite State Automata," JOINTECS (Journal Inf. Technol. Comput. Sci., vol. 3, no. 3, pp. 143-148, 2018, doi: 10.31328/jointecs.v3i3.819.

X. Han, Z. Chen, Z. Liu, and Q. Zhang, "The detection and stabilisation of limit cycle for deterministic finite automata," Int. J. Control, vol. 91, no. 4, pp. 874-886, 2018, doi: 10.1080/00207179.2017.1295319.

B. Satrio and T. H. B. Ongko, "Pengembangan Game Pengenalan Huruf Untuk Anak Usia Dini Berbasis Fsa ( Finite State Automata )," vol. VIII, no. 01, pp. 112-131.

D. Tetap, S. Eresha, D. Tetap, and U. Serang, "Penerapan Algoritma Finite State Automata ( Fsa ) Pada Game Pengenalan Huruf Untuk Pendidikan Anak Usia Dini,” vol. VI, no. 02, pp. 46-57, 2011. 
[9] W. G. Gabriel Vangeran Saragih, Anas Faisal, "Desain Vending Machine Rokok Dengan Mengimplementasikan Finite State Automata," Desain Vend. Mach. Rokok Dengan Mengimplementasikan Finite State Autom. Terintegrasi Dengan E-KTP, vol. 12, no. 1, pp. 55-60, 2020.

[10] M. Nourian, H. Wu, and M. Becchi, "A Compiler Framework for Fixed-Topology Non-Deterministic Finite Automata on SIMD Platforms," Proc. Int. Conf. Parallel Distrib. Syst. - ICPADS, vol. 2018-December, pp. 507-516, 2019, doi: 10.1109/PADSW.2018.8644852.

[11] A. Ardiansyah, N. Hardi, and W. Gata, "Identifikasi dan Recovery File JPEG dengan Metode Signature-Based Carving dalam Model Automata," Komputika J. Sist. Komput., vol. 9, no. 1, pp. 75-83, 2020, doi: 10.34010/komputika.v9i1.2733.

[12] T. Rivanie, T. A. M, and Y. Alkhalifi, "Implementasi Finite State Automata dalam Proses Registrasi Workout Plan pada Pusat Kebugaran," Implementasi Finite State Autom. dalam Proses Regist. Work. Plan pada Pus. Kebugaran, vol. 12, no. 1, pp. 94-98, 2020.

[13] J. H. Ellenberg and K. B. Nelson, "The association of cerebral palsy with birth asphyxia: A definitional quagmire," Dev. Med. Child Neurol., vol. 55, no. 3, pp. 210-216, 2013, doi: 10.1111/dmcn.12016.

[14] R. A. Ma'arif and F. Fauziah, "Implementasi Finite State Automata (FSA) dalam Proses Pengisian Kartu Rencana Studi," JOINTECS (Journal Inf. Technol. Comput. Sci., vol. 3, no. 3, pp. 115-120, 2018, doi: 10.31328/jointecs.v3i3.816.

[15] "Pimpinan Redaksi Faizal Mahananto Dewan Redaksi Eko Wahyu Tyas Darmaningrat Tata Pelaksana Usaha Achmad Syaiful Susanto Rini Ekowati Sekretariat," vol. 08, no. 03, 2019.

[16] A. Ramadhani, H. Q. Yusman, I. V. Putra, and I. Asrowardi, "Aplikasi Online Course ' Waroeng Inggris' Berbasis Web dengan Menggunakan Framework Codeigniter," KARYA Ilm. Mhs. [MANAJEMEN Inform. Tinj., pp. 1-11, 2019.
[17] R. A. W., H. Tolle, and O. Setyawati, "Pengembangan Aplikasi Text-to-Speech Bahasa Indonesia Menggunakan Metode Finite State Automata Berbasis Android," J. Nas. Tek. Elektro dan Teknol. Inf., vol. 5, no. 1, 2016, doi: 10.22146/jnteti.v5i1.179.

[18] I. D. Wisjaya et al., "Simulasi Pembelajaran Berternak Burung Puyuh Menggunakan Metode Finite State Machine Berbasis Android," vol. 6, no. 1, pp. 12-18, 2019, doi: 10.25047/jtit.v6i1.103.

[19] M. Rosmiati and R. S. Atmaja, "Perancangan Animasi Interaktif Pengenalan Pahlawan Nasional Berbasis Android," Semin. Nas. Ilmu Pengetah. dan Teknol. Komput., pp. 175-184, 2016.

[20] D. Sujana, A. Hanipah, E. Dian, A. Suwenti, and S. Y. Aulia, "Analisis Vending Machine Menggunakan Metode Finite State Automata (FSA ) Di Gedung Lama Universitas Islam Syekh Yusuf Tangerang," J. Keilmuan dan Apl. Tek., vol. 6, no. 1, pp. 19-22, 2019.

[21] A. Maezar, B. Aji, V. Riyanto, G. Wijaya, and B. Rudianto, "Rancang Bangun Sistem Informasi Penjualan Produk Percetakan Berbasis Web Dengan Pemodelan UML," vol. 8, no. 1, pp. 56-61, 2018.

[22] G. Wijaya and M. Sari, "Perancangan Sistem Informasi Pengajuan Kredit Berbasis Web Pada PT . BPR Kredit Mandiri Indonesia Cabang Bekasi," IJSE - Indones. J. Softw. Eng., vol. 3, no. 2, pp. 98-104, 2015.

[23] Sahrul, Karimah, F., Muhazabah, A., Prasetyo, A. D., Yunita, A., \& Zahra, N. L. "PENGEMBANGAN APLIKASI PERMAINAN 'PILAH SAMPAH' MENGGUNAKAN PEMODELAN FINITE STATE MACHINE". Jurnal Teknologia, 1(1), 38-46, 2018. 